\title{
Changes of Shoulder Muscles Activity during Maintaining and Lifting Shoulder Depending on Stretch Rate of Kinesio Tape
}

\author{
Ju-Seung Kim¹, Min-Chull Park² \\ 'Department of Physical Therapy, Graduate School, Catholic University of Pusan; ${ }^{2}$ Department of Physical Therapy, College of Health Sciences, \\ Catholic University of Pusan, Busan, Korea
}

Purpose: The objective of this study was to examine the changes in muscle activity on the anterior deltoid muscle depending on the stretch rate of kinesio tape when applying kinesio tape in healthy adult subjects.

Methods: This study was a single-blind randomized controlled trial, including 22 healthy participants (male 15, female 7) with no pathology or past history of shoulder who participated voluntarily. Participants applied a different stretch rate of the kinesio tape, and the functional activity was tested. The stretch rate of kinesio tape was $0 \%, 10 \%$, and 20\%. Subjects lifted a weight (5\% of their body weight) to their shoulder height. Subjects lifted a weight up to an angle of 90 degrees in the sagittal plane, and muscle activities (biceps brachii, anterior deltoid, middle deltoid, upper trapezius) were assessed using EMG (electromyography). Analysis of muscle activity was divided into two parts (lift weight and keep holding). The EMG activity of each muscle was normalized to the value of reference voluntary contraction (\%RVC) and explored using repeated ANOVA.

Results: There were no significant differences in muscle activity depending on the ratio of tape stretch when lifting a weight ( $p>0.05$ ). There were no significant differences in muscle activity depending on the ratio of tape stretch when holding a weight ( $p>0.05$ ).

Conclusion: According to the results of this study, in the case of applying kinesio taping therapy for healthy people, it was found that the stretch rate of the tape does not have an effect on muscle activity.

Keywords: Deltoid muscle, Electromyography, Muscle activity

\section{서 론}

일상 생활 수행을 위해 팔의 역할은 매우 중요하며, 특히 뻗기는 손을 이용한 조작과 결합 되어 팔 기능에 중요한 역할을 한다. 뻗기는 어깨 와 팔꿈치의 근육들이 방향, 거리, 움직임에 걸리는 시간에 따라 적절 한 패턴을 만들어 활성화 되고 움직이는 것이다. ${ }^{2}$ 이는 일상 생활에서 필요한 기본적인 동작이며, 많은 팔 분절들의 협응력이 필요한 움직임 이다. ${ }^{3}$ 뻗기는 과제 및 자세에 따라서 다르게 나타날 수 있고, ${ }^{4}$ 과제의 위치에 따라 분절들의 움직임과 근육의 활성화 정도가 달라지는데, 대체적으로 어깨세모근의 앞섬유와 가운데섬유 그리고 큰가슴근과 위팔두갈래근, 부리위팔근 등이 중요한 근육으로 작용한다.5 그중에 서도 어깨세모근 앞섬유는 전방 뻗기 시 팔이 시상면을 따라 움직일 수 있게작용하는 근육으로, 전방으로 뻗기에 중요한 역할을 한다.78

테이핑은 주로 비탄력 테이프와 탄력 테이프를 이용하는 방법이
있는데, 비탄력 테이프는 대부분 고정 및 보호를 위해 사용되고, 탄 력 테이프는 혈액 및 림프액 순환의 촉진, 통증 감소, 관절 가동범위 증진, 근력 증진 등을 목적으로 사용된다.9-11 키네시오 테이핑은 테이 프의 원래 길이의 약 $130-140 \%$ 까지 늘어날 수 있는 탄력 테이프를 사 용하여 근육에 부착하는 방법으로, Kase에 의해 고안되었다. ${ }^{12}$

Park과 $\mathrm{Bae}^{13}$ 는 목빗근의 근막 통증에 키네시오 테이핑 적용이 통 증을 감소시키고 호흡 기능에 변화를 일으킨다고 하였으며, Lee 등 ${ }^{14}$ 은 근막통 증후군에 테이핑이 효과가 있다고 하였다. 그러나 Akbas 등 15 은 테이핑 적용군과 비적용군에서 통증 변화에 차이가 없다고 하였다. Kuo와 Huang ${ }^{16}$ 은 근활성도와 근력 증가에 긍정적인 효과가 있다고 하였고, Lee 등 ${ }^{17}$ 은 모지 수근중수관절의 관절가동범위와 악 력 증진 효과가 있다고 하였다. 그러나 이와는 반대로 Gómez-Soriano 등 ${ }^{18}$ 은 키네시오 테이핑의 적용이 건강한 사람의 근력과 유연성, 그리 고 근 긴장도에 영향을 주지 않는다고 하였다.
Received Sep 15, 2015 Revised Oct 6, 2015

Accepted Oct 11, 2015

Corresponding author Min-Chull Park

E-mail mcpark@cup.ac.kr
Copylight (C)2015 The Korea Society of Physical Therapy

This is an Open Access article distribute under the terms of the Creative Commons Attribution Non-commercial License (Http:// creativecommons.org/license/by-nc/3.o.) which permits unrestricted non-commercial use, distribution, and reproduction in any medium, provided the original work is properly cited. 
Huang 드이은 장딴지근에 탄력 테이프를 적용하였을 때 안쪽 장딴 지 근의 근전도 신호가 증가되었다고 하였고 Kwon 등19은 테이핑 적 용이 근력과 지구력의 증진에 효과가 있다고 하였다. 그러나 Poon 등 ${ }^{20}$ 의 연구에 의하면 탄력 테이프를 넙다리 네갈래근에 적용하였을 때 일량과 최대 회전력의 변화가 없었다고 하였고, Vercelli 등ㄹㅇㅢ 연 구에서도 테이핑 적용이 넙다리 네갈래근의 근력과 기능에 유의한 변화를 이끌어 내지 못하였다고 하였다. 이처럼 키네시오 테이핑은 많은 연구자들에 의해 통증, 관절가동범위, 기능, 근활성도 등에 미치 는 효과를 확인하기 위해 활발하게 연구되어 왔으나 연구자마다 다 양한 결과들을 제시하고 있다.

$\mathrm{Hsu}$ 등 22 은 17 명의 어깨 충돌 증후군이 있는 야구선수에게 키네시 오 테이프를 최소한 신장한 상태로 적용하였을 때 근육의 수축을 지 지하여 근활성도와 근력의 증가를 볼 수 있었다고 하였다. 그리고 Mohammadi 등 23 은 40명의 건강한 성인에게 키네시오 테이프를 50\% 늘려 적용하여 악력의 증가를 볼 수 있었다고 하였다. 이처럼 선행 연 구들에서 테이프의 적용 길이를 제시하고 있지만 신장 정도를 다르 게 하였을 때의 영향을 본 연구는 거의 없었다. 테이프를 늘려서 근육 주행 방향을 따라 적용하면 피부를 들어올리고 압력을 감소시켜 혈 액 및 림프액의 순환을 증가시키고, 통증완화 및 2 차적인 손상 예방 과 기능 증진을 이끌어 낼 수 있는데, ${ }^{12}$ 테이프를 신장할수록 탄력 테 이프의 줄어드는 성질에 의해 지속적인 기계적 자극이 가해질 것이 고 피부에 가해지는 자극은 일차 감각, 운동 피질을 포함한 뇌의 다 양한 부위에 활성도를 증가시킬 것이다.24,25 이에 본 연구에서는 어깨 에 손상이 없는 건강한 성인 남녀를 대상으로 전방으로 팔을 뻗는 동 작을 수행할 때 어깨세모근 앞섬유에 신장 정도를 달리한 테이프를 적용하여 근활성도의 변화를 확인해 보고자 하였다. 이를 통해 적절 한 테이핑의 적용 방법을 위한 기초 자료를 제공하고자 수행되었다.

\section{연구방법}

\section{1. 연구 대상}

본 연구 대상자는 뉘른베르크 강령에 따라 실험의 목적과방법에 대해 충분한 설명을 듣고 이해한 다음 자발적으로 참여에 동의한 22 명 (남 자 15 명, 여자 7 명)의 건강한 사람을 대상으로 하였다. 대상자의 선정 조 건은 최근 6 개월 이내에 어깨의 통증을 경험하지 않은 자, 어깨의 수동, 능동적 관절 가동범위에 이상이 없는 자, 어깨의 질환 및 수술 받은 적 이 없는 자로 하였다. 대상자의 일반적 특성은 다음과 같다(Table 1).

\section{2. 실험방법}

\section{1) 실험절차}

측정은 실험에 영향을 미칠 수 있는 환경적인 영향을 최소화하기 위
Table 1. General characteristics of subjects

\begin{tabular}{lccc}
\hline $\mathrm{n}$ & Age & Height $(\mathrm{cm})$ & Weight $(\mathrm{kg})$ \\
\hline $22(\mathrm{M} \mathrm{15,} \mathrm{F} \mathrm{7)}$ & $27.40 \pm 4.23$ & $169.55 \pm 7.97$ & $66.77 \pm 13.22$ \\
\hline
\end{tabular}

해 소음이 없는 실험실에서 실험에 필요한 것 이외에 다른 전자 기기 의 전원을 끄고, 실내 온도는 $24^{\circ} \mathrm{C}$ 로 통일하여 진행하였다. 대상자는 의복을 최소화 하고, 등받이가 없고 높이 조절이 가능한 의자에 엉덩 관절 굽힘 $90^{\circ}$ 와 무릎관절 굽힘 $100^{\circ}$ 각도로 유지하고 앉아 시작 자 세를 취하였다. 앞팔은 중립 자세로 어깨굽힘 $0^{\circ}$ 에서 시작하였고 연 구자의 신호에 따라 어깨굽힘을 시작하였다. 모든 대상자들은 실험 방법의 동질화를 위해 우세측 팔을 이용하여 어깨 관절의 굽힘 동안 팔과 어깨 근육의 근활성도를 기록하였다. 대상자들은 체중의 $5 \%$ 가 되는 무게추를 손목에 달고 어깨 관절을 굽힘 시 등세모근 위섬유와 어깨세모근 가운데섬유의 보상작용을 최소화하기 위해서 ${ }^{26}$ 가능한 시상면을 따라 움직임이 일어날 수 있도록 전방에 기준 봉을 세우고 어깨 관절 $90^{\circ}$ 가 되는 높이를 봉에 표시하여 일정한 높이까지 팔을 들어올리게 하였다. 테이핑의 적용을 위해 앞팔의 중립과 어깨 굽힘 $0^{\circ}$ 로 하고 어깨세모근 거친면에서 빗장뼈 외측 $1 / 3$ 지점까지 길이를 측정하여 5 인치 넓이의 키네시오 테이프(M-TEX, mkorea, korea)를 길 이에 맞게 준비하였다. 테이프의 신장 정도를 달리하여 적용하기 위 해 원래 준비한 길이에서 $10 \%, 20 \%$ 를 자른 길이의 테이프를 똑같은 방법으로 어깨세모근에 늘려서 부착하여 근활성도 측정을 하였다. 한쪽 끝에 $20 \%$ 를 남기고 나머지 부위를 두 갈래가 되도록 균등하게 나누었다. 자르지 않은 부분을 어깨세모근 거친면부터 붙이고 측정 하고자 하는 쪽 엄지 손가락을 반대쪽 무릎에 두어 어깨를 굽힘, 모 음, 안쪽 돌림 한 상태에서 잘린 테이프의 뒤쪽을 어깨세모근 뒤섬유 를 따라 어깨뼈 가시까지 붙이고 어깨를 최대한 신전, 가쪽돌림한 상 태에서 잘린 테이프의 앞쪽을 어깨세모근 앞섬유를 따라 빗장벼 외 측 $1 / 3$ 지점까지 늘려서 붙였다. 테이프 길이에 따른 적용 순서는 추첨 을 통해 무작위로 하고 적용 방식마다 근활성도를 측정하였으며 각 5 분의 간격을 주어 대상자에게 충분한 휴식을 제공하였다. 팔을 들어 올릴 때 어깨에 막대를 대어 어깨뼈의 올림을 통제하였다.

\section{2) 측정도구 및 방법}

팔과 어깨 근육의 수축 시 활성도를 알아보기 위해 4 채널 근전도를 사용하였다. 전극을 부착하기 전에 피부의 저항을 줄이기 위해 털을 제거하고 알코올로 소독하였다. 은/연화은 표면 전극을 사용하여 수 축이 일어나는 쪽의 등세모근 위섬유(upper trapezius), 어깨세모근의 앞섬유(anterior deltoid)와 가운데섬유(middle deltoid), 위팔두갈래근 (biceps brachii)에 부착하였다. 전극 간의 거리는 $2 \mathrm{~cm}$ 로 유지하여 근 섬유 방향에 평행하게 부착하였다. 근활성도의 측정은 표면 무선 근 
전도 시스템(Telemyo 2400T-G2 dynamic EMG, Noraxon Inc., USA)을 사용하였다. 근전도 신호의 표본 추출률은 $1,024 \mathrm{~Hz}$ 로 설정하였고 주 파수 대역 필터로 $10-250 \mathrm{~Hz}$ 를 설정하여 주파수 대역을 지정하였다. 근활성도는 무게추를 손목에 달고 연구자의 신호에 따라 편안한 속 도로 굽힘 $90^{\circ}$ 로 봉에 표시한 지점까지 팔을 올리고 7초간 유지하기 를 3 회 반복할 때 측정하였다. 뻗기( 2 초)와 유지하기(5초)의 두 구간으 로 나누어 제곱 평균 제곱근법(root mean square)으로 처리하여 분석 하였다. 근활성도의 정규화를 위한 기준 수축 역시 같은 방법으로 테 이핑을 하지 않은 상태에서 무게추를 들고 연구자의 신호에 따라 팔 을 들어올릴 때로 정하였다. 기준 수축은 뻗어서 5 초 유지할 때의 근 활성도로 정하고 비교하였다. 네 개의 근육에 대한 근활성도를 정규 화 하기 위해 기준 수축을 하는 동안 수집된 값으로 정량화한 \%RVC (reference voluntary contraction)로 기록하였다.

\section{3) 자료분석}

본 연구에서 수집된 자료들은 SPSS ver. 21.0 프로그램을 사용하여 분 석하였다. 대상자의 일반적 특성은 평균값과 표준편차로 표시하였 다. 테이핑의 적용 방식에 따른 근활성도의 차이는 반복측정 분산분 석(repeated one-way ANOVA)을 이용하여 비교하였으며 통계적 유의 수준 $\alpha=0.05$ 로 정하였다.

\section{결 과}

\section{1. 팔 뻗기 동안 테이프 신장비율에 따른 근활성도 변화}

팔뻗기 동안 어깨세모근 앞섬유와 가운데섬유, 위팔두갈래근, 등세 모근 위섬유의 근활성도는 테이프 신장비율에 따라 유의한 차이가 없었다 $(\mathrm{p}>0.05)$ (Table 2$)$.

\section{2. 팔 뻗기를 유지하는 동안 테이프 신장비율에 따른 근활성도 변화}

팔뻗기를 유지하는 동안 어깨세모근 앞섬유와 가운데섬유, 위팔두 갈래근, 등세모근 위섬유의 근활성도는 테이프 신장비율에 따라 유 의한차이가 없었다( $p>0.05)$ (Table 3$)$.

\section{고 찰}

근전도를 사용한 연구에서는 주로 최대 등척성 수축을 사용한 $\% \mathrm{MVIC}$ (maximum voluntary contraction)와 기준이 되는 동작을 사 용한 \%RVC 방법을 통해 근육의 활성화 정도를 비교해왔다. 근전도 신호의 증가는 근육의 활성화 정도를 의미하는 것으로 신호의 증가 가 항상 근력이 증가하였다거나 근력이 상대적으로 크다는 것을 뜻 하지는 않는다. Arab 등 27 의 연구에서처럼 누운 자세에서 다리 뒤로 들기 시 요통이 있는 사람의 척추 세움근의 근전도 신호가 정상인에 비해 크다는 것은 같은 동작을 할 때 요통이 있는 사람이 그 근육을 더 많이 사용함을 뜻한다.

테이핑으로 인한 몸감각 자극은 겉질 운동 표상 영역의 활성도를 증가시켜 운동 수행력을 향상시키고, ${ }^{28}$ 테이핑의 지지력과 탄성이 관 절의 안정성과 근골격계의 좋은 정렬 상태를 만들어 신경근 기능 증 진을 이끌어 낸다.11 그러나 근력, ${ }^{20,29}$ 관절가동범위, ${ }^{30}$ 통증, ${ }^{15}$ 부종의 감소 ${ }^{31}$ 에서 테이핑이 항상 긍정적인 효과만을 볼 수는 없다는 연구도 최근에 많이 발표되고 있다.

$\mathrm{Kase}^{12}$ 에 따르면 관절 완전 가동범위를 가능하게 하기 위해서 키네 시오 테이프는 130-140\%까지 신장할 수 있다고 하였다. 과사용, 급성 손상 시에는 신장 없이, 만성 및 급성 약화가 있을 때는 $15 \%$ 정도 늘려 서, 관절이나 인대의 손상에서는 최대한 테이프를 늘려 적용하라고 제시하였다. 또한 근력의 증가를 위해서는 $35 \%$ 또는 50-75\%로 테이프

Table 2. Comparison of shoulder muscle activity during lifting shoulder depending on kinesiotape stretching rate (mean $\pm S D)$

(Unit: \%RVC)

\begin{tabular}{|c|c|c|c|c|c|}
\hline Stretch rate & $0 \%$ & $10 \%$ & $20 \%$ & $\mathrm{~F}$ & $\mathrm{p}$ \\
\hline Biceps & $98.66 \pm 15.75$ & $98.81 \pm 12.20$ & $98.30 \pm 16.76$ & 0.015 & 0.985 \\
\hline Anterior deltoid & $102.55 \pm 15.33$ & $105.85 \pm 17.08$ & $104.67 \pm 21.02$ & 0.358 & 0.646 \\
\hline Middle deltoid & $99.36 \pm 15.91$ & $103.85 \pm 18.09$ & $98.55 \pm 17.24$ & 0.722 & 0.492 \\
\hline Upper trapezius & $96.19 \pm 21.90$ & $101.40 \pm 17.91$ & $93.31 \pm 16.90$ & 2.055 & 0.141 \\
\hline
\end{tabular}

RVC: Reference voluntary contraction.

Table 3. Comparison of shoulder muscle activity during maintaining shoulder depending on kinesiotape stretching rate (mean \pm SD) (Unit: \% RVC)

\begin{tabular}{lccccc}
\hline Stretch rate & $0 \%$ & $10 \%$ & $20 \%$ & $\mathrm{~F}$ & $\mathrm{p}$ \\
\hline Biceps & $100.30 \pm 12.94$ & $98.22 \pm 10.30$ & $97.07 \pm 9.40$ & 1.111 & 0.339 \\
Anterior deltoid & $100.75 \pm 9.41$ & $104.40 \pm 9.32$ & $101.64 \pm 9.23$ & 9.006 & 0.147 \\
Middle deltoid & $97.15 \pm 6.90$ & $100.08 \pm 6.55$ & $96.72 \pm 8.51$ & 2.299 & 0.113 \\
Upper trapezius & $96.19 \pm 14.44$ & $98.66 \pm 15.69$ & $97.73 \pm 11.78$ & 0.440 & 0.578 \\
\hline
\end{tabular}

RVC: Reference voluntary contraction. 
를 늘려야 한다는 등 적용 길이에 대한 여러 주장들이 있다. ${ }^{20}$

$\mathrm{Cai}$ 등 32 에 따르면 건강한 성인의 손목 신전근에 테이핑을 적용하 고 악력과 근전도 신호를 분석한 결과 근력과 근활성도의 차이를 볼 수 없었다. 그리고 Oliveria 등 ${ }^{33}$ 의 연구에서 대퇴 사두근에 테이핑을 하였을 때 최대 근력과 근활성도의 변화가 없었다. 본 연구에서는 신 장 정도를 다르게 한 테이핑을 어깨세모근 앞섬유에 적용하고 팔 들 기 시 어깨세모근 앞섬유와 가운데 섬유, 위팔두갈래근, 등세모근 위 섬유의 근전도 신호를 \%RVC 방법을 통해 분석하였는데 유의한 차이 를볼수없었다.

테이핑으로 가해진 긴장과 자극으로 움직임 패턴의 변화가 생길 수 있는데, 이것이 만들어지기 위해서는 충분한 시간과 반복이 필요 하다. ${ }^{34}$ 또한 테이핑 적용 후 일정 시간 후에 근육의 긴장도는 점차 증 가하는데, 24 시간 이내에는 긴장도에 영향을 주지 못하며 24시간 이 후 72 시간까지 적용한다면 근전도 신호의 증가를 보일 것이다. ${ }^{35}$ 본 연 구는 정상 성인을 대상으로 하였는데 통증이 있거나 신체 정렬에 문 제가 있는 사람에게 테이핑의 적용은 잘못된 위치를 바로잡아 역학 적 이득을 얻고 관문 조절 기전에 의한 통증 감각의 차단으로 더욱 큰 근육의 활동을 만들 수 있지만, 정상인에게는 그 효과가 미비하여 근활성도에 유의한차이가 없었던 것으로 여겨진다. ${ }^{36}$

신경 전도 검사는 말초신경의 전기 자극에 의해 유발된 전위를 기 록하여 운동 신경과 감각 신경의 기능을 평가하는 것이다. 운동 신경 전도 검사에서 잠복시의 감소, 진폭과 속도의 증가는 운동 신경원의 흥분성 증가를 뜻한다. 운동 신경원의 흥분으로 근육의 신경 근 접합 부로 전달 된 신호를 통해 근육은 활성화 되고 이때 발생하는 활동전 위를 근전도를 통해 기록할 수 있다. 37,38 그러나 실험에서 테이핑의 적 용이 운동 신경원의 흥분성과 근육 세포의 활동전위에 변화를 줄만 큼 강하지 못해 근전도 신호의 차이를 볼 수 없었다고 사료된다..$^{39}$ 또 한 겉질 척수로의 흥분성을 변화시키는데 영향을 미칠 수 있는 테이 핑으로 인한자극의 크기가 충분하지 못하였을 것이다. ${ }^{40}$

본 연구에는 다음의 제한점이 있다. 대상자의 수가 적어 이를 일반 화하기에는 어려움이 있으며, 테이프의 신장 적용시 과도한 테이프의 장력으로 인한 관절 운동의 보조적인 역할을 최소화하기 위해 $0 \%$, $10 \%, 20 \%$ 로 하였는데 관절 가동범위가 허용하는 범위까지 몇 단계를 더 추가하여 적용해 보았다면, 적용 방식에 따른 차이를 더욱 세밀하 게 분석 할수 있었을 것이다.

비록 정상인을 대상으로 한 본 연구에서 테이핑의 적용으로 근활 성도에 유의한 차이를 볼 수는 없었지만 작은 차이에 의해서도 많은 영향을 받는 운동선수나 환자에게 키네시오 테이프를 적용하는 추 후 연구도 필요할 것이다.

결론적으로 정상인을 대상으로 키네시오 테이프를 어깨세모근의 앞섬유에 적용하고 팔 뻗기를 수행하였을 때 $10 \%, 20 \%$ 로 신장시킨 테
이핑의 적용은 근활성도에 영향을 미치지 않음을 확인할 수 있었다.

\section{REFERENCES}

1. Jeong JY, Lee HC, Shin HK. The effects of seat surface inclination on forward reaching in children with spastic cerebral palsy. J Kor Phys Ther. 2015;27(2):106-11.

2. Buneo CA, Soechting JF, Flanders M. Muscle activation patterns for reaching: The representation of distance and time. J Neurophysiol. 1994;71(4):1546-58.

3. Flash T, Hogan N. The coordination of arm movements: An experimentally confirmed mathematical model. J Neurosci. 1985;5(7):1688-703.

4. Weon JH, Oh JS, Cynn HS et al. Influence of forward head posture on scapular upward rotators during isometric shoulder flexion. J Bodyw Mov Ther. 2010;14(4):367-74.

5. Vandenberghe A, Levin O, De Schutter J et al. Three-dimensional reaching tasks: Effect of reaching height and width on upper limb kinematics and muscle activity. Gait Posture. 2010;32(4):500-7.

6. Bonnefoy A, Louis N, Gorce P. Muscle activation during a reach-tograsp movement in sitting position: Influence of the distance. J Electromyogr Kinesiol. 2009;19(2):269-75.

7. Park MC, Lee MH, Song MY et al. The comparison of muscle activation on low-reaching and high-reaching in patient with stroke. J Phys Ther Sci. 2010;22(3):291-4.

8. Wagner JM, Dromerick AW, Sahrmann SA et al. Upper extremity muscle activation during recovery of reaching in subjects with post-stroke hemiparesis. Clin Neurophysiol. 2007;118(1):164-76.

9. Choi JH, Lee JK. The effect of a kinesio taping on muscle power and muscular fatigue in quadriceps femoris. The Korean Academy of Physical Therapy Science. 2008;15(4):19-26.

10. Campolo M, Babu J, Dmochowska K et al. A comparison of two taping techniques (kinesio and mcconnell) and their effect on anterior knee pain during functional activities. Int J Sports Phys Ther. 2013;8(2):105-10.

11. Huang CY, Hsieh TH, Lu SC et al. Effect of the kinesio tape to muscle activity and vertical jump performance in healthy inactive people. Biomed Eng Online. 2011;10(1):70.

12. Kase K, Wallis J, Kase T. Clinical therapeutic applications of the kinesio taping methods. 2nd ed. Kinesio Taping Assoc. 2003.

13. Park YN, Bae YS. Change of pain and breathing function following kinesio taping of myofascial pain in sternocleidomastoid muscle. J Kor Phys Ther. 2014;26(5):302-7.

14. Lee JH, Hwang KO, Park YH. Comparing the effects of stability exercise, ESWT, and taping for patients with myofascial pain syndrome of upper trapezius. J Kor Phys Ther. 2012;24(2):82-9.

15. Akbas E, Atay AO, Yuksel I. The effects of additional kinesio taping over exercise in the treatment of patellofemoral pain syndrome. Acta Orthop Traumatol Turc. 2011;45(5):335-41.

16. Kuo YL, Huang YC. Effects of the application direction of kinesio taping on isometric muscle strength of the wrist and fingers of healthy adults-a pilot study. J Phys Ther Sci. 2013;25(3):287-91.

17. Lee MH, Kim EC, Lee SY et al. The effects of taping on metacarpophalangeal disorders of the thumb. J Kor Phys Ther. 2010;22(1):33-8.

18. Gómez-Soriano J, Abián-Vicén J, Aparicio-García C et al. The effects of 
kinesio taping on muscle tone in healthy subjects: a double-blind, placebo-controlled crossover trial. Man Ther. 2014;19(2):131-6.

19. Kwon HJ, Park DS, Jeong JR et al. The effect of silicone sleeve and taping on balance and strength in anterior cruciate ligament reconstruction patients. J Kor Phys Ther. 2014;26(3):147-55.

20. Poon KY, Li SM, Roper MG et al. Kinesiology tape does not facilitate muscle performance: A deceptive controlled trial. Man Ther. 2015;20(1): 130-3.

21. Vercelli S, Sartorio F, Foti C et al. Immediate effects of kinesiotaping on quadriceps muscle strength: A single-blind, placebo-controlled crossover trial. Clin J Sport Med. 2012;22(4):319-26.

22. Hsu YH, Chen WY, Lin HC et al. The effects of taping on scapular kinematics and muscle performance in baseball players with shoulder impingement syndrome. J Electromyogr Kinesiol. 2009;19(6):1092-9.

23. Mohammadi HK, Kalantri KK, Neaimi SS et al. Immediate and Delayed Effects of Forearm Kinesio Taping on Grip Strength. Iran Red Crescent Med J. 2014;16(8):e19797.

24. Lee MS. Effects of kinesio taping on muscle strength improvement, and the blood markers of muscle fatigue and damage. Yonsei university. Dissertation of Doctorate Degree. 2007.

25. Wardman DL, Gandevia SC, Colebatch JG. Cerebral, subcortical, and cerebellar activation evoked by selective stimulation of muscle and cutaneous afferents: An fMRI study. Physiol Rep. 2014;2(4):e00270.

26. Weon JH, Jung DY. Comparison of the muscle activities of upper trapezius and middle deltoid between subjects with and without elevation of shoulder girdle during arm elevation. J Kor Phys Ther. 2012;24(6):38892.

27. Arab AM, Ghamkhar L, Emami M et al. Altered muscular activation during prone hip extension in women with and without low back pain. Chiropr Man Therap. doi:10.1186/2045-709X-19-18.

28. Kaelin-Lang A, Luft AR, Sawaki L et al. Modulation of human corticomotor excitability by somatosensory input. J Physiol. 2002;540(2):623-33.

29. Wong OMH, Cheung, RTH, Li RCT. Isokinetic knee function in healthy subjects with and without kinesio taping. Phys Ther Sport. 2012;13(4): 255-8.

30. Alam S, Malhotra D, Munjal J et al. Immediate effect of kinesio taping on shoulder muscle strength and range of motion in healthy individuals: a randomised trial. Hong Kong Physiotherapy Journal. doi:10.1016/ j.hkpj.2014.10.004.

31. Nunes GS, Vargas VZ, Wageck B et al. Kinesio Taping does not decrease swelling in acute, lateral ankle sprain of athletes: A randomised trial. J Physiother. 2015;61(1):28-33.

32. Cai C, Au IP, An W et al. Facilitatory and inhibitory effects of Kinesio tape: Fact or fad?. J Sci Med Sport. doi: 10.1016/j.jsams.2015.01.010.

33. Oliveira AK, Borqes DT, Lins CA et al. Immediate effects of Kinesio Taping on neuromuscular performance of quadriceps and balance in individuals submitted to anterior cruciate ligament reconstruction: A randomized clinical trial. J Sci Med Sport. doi: 10.1016/j.jsams.2014.12.002.

34. Morrissey D. Proprioceptive shoulder taping. J Bodyw Mov Ther. 2000; 4(3):189-94.

35. Słupik A, Dwornik M, Białoszewski D et al. Effect of kinesio taping on bioelectrical activity of vastus medialis muscle. preliminary report. Ortop Traumatol Rehabil. 2006;9(6):644-51.

36. Chen PL, Hong WH, Lin CH et al. Biomechanics effects of kinesio taping for persons with patellofemoral pain syndrome during stair climbing. In 4th Kuala Lumpur International Conference on Biomedical Engineering. Springer Berlin Heidelberg. 2008:395-97.

37. Kim HB, Park YH, Bae SS. Clinical application of electromyography and nerve conduction study. J Kor Phys Ther. 1998;10(1):199-212.

38. Kim KN. Principles and clinical applications of electromyography. The journal of korean academy of craniomandibular disorders. 1999;11(1): $35-46$.

39. Lee MH, Lee CR, Park JS et al. Influence of kinesio taping on the motor neuron conduction velocity. J Phys Ther Sci. 2011;23(2):313-5.

40. Tremblay F, Karam S. Kinesio-taping application and corticospinal excitability at the ankle joint. J Athl Train. 2015;50(8):840-6. 